\title{
The relationship between death anxiety and level of self-esteem: A reassessment
}

\author{
VICTORIA L. BUZZANGA, HOLLY R. MILLER, SHARON E. PERNE, \\ JULIE A. SANDER, and STEPHEN F. DAVIS \\ Emporia State University, Emporia, Kansas
}

\begin{abstract}
A total of 157 undergraduates (58 men, 99 women) completed self-esteem and death anxiety testing instruments. In agreement with previous research, it was found that women had higher death anxiety scores than men, and that subjects low in self-esteem had higher death anxiety scores than those high in self-esteem. Unlike previous research, the present data failed to yield a significant difference in level of self-esteem between men and women.
\end{abstract}

For nearly six decades, psychologists have examined the fear of death. Not surprisingly, much of this research has been done in the attempt to determine what, if any, relationship exists between death anxiety and a wide variety of personality factors. For example, Middleton (1936) demonstrated that during periods of depression and/or following an accident, the frequency of thinking about one's own death escalated rather drastically.

During the 1970s and early 1980s, a sizeable number of studies employed the Death Anxiety Scale (DAS), developed by Templer (1970), to evaluate the fear of death. In turn, this empirical measure of death anxiety has been related to a wide range of variables. For example, it was shown that the death anxiety of people engaged in highrisk occupations, such as career military officers (Koob \& Davis, 1977) and policemen (Ford, Alexander, \& Lester, 1971), was no higher than that of many groups having less risky occupations.

Sadowski, Davis, and Loftus-Vergari (1979) examined the relationship between DAS scores and locus of control. Reflecting a concern over the individual's inability to determine his or her own behavior, the results indicated that DAS scores were positively related to scores on the self-control dimension of the Reid-Ware Three Factor Locus of Control Scale (Reid \& Ware, 1973). Davis, Bremer, Anderson, and Tramill (1983) reported a strong negative relationship between ego strength and DAS scores. In a related investigation, Tramill, Davis, Bremer, Dudeck, and Elsbury (1982) reported a strong positive relationship between DAS scores and scores on the short form of the Taylor Manifest Anxiety Scale (Hicks, Ostle, \& Pellegrini, 1980). As higher levels of manifest anxiety might be expected to be shown by those who have lower self-control, these two results seem quite compatible. This general pattern of perceived loss or lack of control associated with higher DAS scores leads to the prediction by Tramill, Kleinhammer-Tramill, Davis, Parks, and Alexander (1984) that the accomplishment-driven Type A

Correspondence may be addressed to Stephen F. Davis, Division of Psychology, Emporia State University, Emporia, KS 66801-5087. individual who actively strives to maintain control over his or her environment also would display high DAS scores. This prediction was substantiated.

Two additional findings are of more direct relevance to the present study. First, several investigators (e.g., Koob \& Davis, 1977; Schulz, 1978; Templer, Lester, \& Ruff, 1974) have found that women expressed greater death anxiety than did men. Second, Davis et al. (1983), and Davis, Martin, Wilee, and Voorhees (1978) found that men had significantly higher self-esteem scores than did women. Additionally, in both of these studies, Davis and colleagues reported a significant, negative relationship between death anxiety and self-esteem. Clearly, major social changes have taken place in our society since those data were reported. Women have made, and are continuing to make, a significant and positive impact in the work force. In the field of psychology, for example, most institutions currently report that at least two-thirds of all undergraduate majors are women (Howard et al., 1986). Likewise, the number of PhDs in psychology received each year by women now equals the number received by men (Howard et al., 1986). Similar statements could be made for other areas, such as sports, politics, and the media. The prevalence of more numerous, positive female role models suggests the possibility that the general level of self-esteem may have increased for women during recent years. On the basis of the reported negative relationship between death anxiety and level of self-esteem, it seems reasonable to propose that gender differences in death anxiety also may have become less pronounced in recent years. In the present study, we sought to investigate these possibilities.

\section{METHOD}

\footnotetext{
Subjects

The subjects were 157 undergraduate college students ( 58 men, 99 women) enrolled at Emporia State University. All students volunteered to participate in the study.

Testing Instruments

The DAS and the Texas Social Behavior Inventory (TSBI; Helmreich \& Stapp, 1974) were used to measure death anxiety and self-esteem,
} 
respectively. The DAS has 15 true-false items and has a test-retest reliability of .83 (Templer, 1970). The TSBI is a 16-item Likert-type scale designed "to provide an objective measure of self-esteem or social competence"' (Helmreich \& Stapp, 1974). In both cases, higher scores are associated with higher levels of the characteristic being measured.

\section{Procedure}

Testing took place during a regular class period. The test instruments were combined into a booklet with a survey on cheating and were selfadministered. Hence, no instructions, other than those pertaining to the distribution of the booklets, were provided by the investigators.

\section{RESULTS}

Means and standard deviations for DAS and TSBI scores for the entire sample of men and women are shown in Table 1. A separate, unweighted means analysis of variance was performed on each of these sets of data. Analysis of the DAS scores yielded significance for the gender factor $[F(1,156)=18.01, p<.001]$, but analysis of the TSBI scores failed to yield a reliable difference between men and women $[F(1,156)=3.07, p=.08]$.

Following these general analyses, the samples of men and women were divided into high and low self-esteem subgroups. High and low self-esteem were defined as scores one standard deviation above and below the group's mean score, respectively. The mean DAS score for each of these subgroups is shown in Table 2 . In turn, these scores were subjected to a $2 \times 2$ factorial analysis of variance, incorporating gender (men-women) and self-esteem (low-high) as factors. The results of this analysis yielded significance for both the self-esteem $[F(1,40)=9.10, p$ $=.004]$ and gender $[F(1,40)=19.30, p<.001]$ effects. Inspection of Table 2 will indicate that subjects with high self-esteem had significantly lower DAS scores than did subjects with low self-esteem. In accord with the analysis of the entire sample, it also can be seen that, regardless of the level of self-esteem, women reported higher levels of death anxiety than did men.

Table 1

Means and Standard Deviations for Death Anxiety (DAS) and Self-Esteem (TSBI) Scores for the Entire Sample of Men and Women

\begin{tabular}{|c|c|c|c|c|c|}
\hline & \multirow[b]{2}{*}{$n$} & \multicolumn{2}{|c|}{ Death Anxiety } & \multicolumn{2}{|c|}{ Self-Esteem } \\
\hline & & Mean & $S D$ & Mean & $S D$ \\
\hline Men & 58 & 5.74 & 2.99 & 41.43 & 5.80 \\
\hline Women & 99 & 7.99 & 3.33 & 39.73 & 5.93 \\
\hline
\end{tabular}

Table 2

Mean Death Anxiety (DAS) Scores and Standard Deviations for Men and Women with High or Low Self-Esteem

\begin{tabular}{lrrrrrrr} 
& \multicolumn{3}{c}{ Low Self-Esteem } & & \multicolumn{3}{c}{ High Self-Esteem } \\
\cline { 2 - 4 } \cline { 6 - 8 } & $n$ & Mean & $S D$ & & $n$ & Mean & $S D$ \\
\hline Men & 9 & 7.44 & 1.00 & 9 & 5.00 & 1.80 \\
Women & 11 & 9.91 & 2.77 & 15 & 6.53 & 2.29 \\
\hline
\end{tabular}

\section{DISCUSSION}

Since the present study closely paralleled the report by Davis et al. (1978), similarities and differences between these two sets of data will be highlighted. In both studies, it was found that subjects with low selfesteem had significantly higher death anxiety than did subjects with high self-esteem. The replicability of this finding contrasts with the proposition, offered by Diggory and Rothman (1961), that persons who value themselves highly should display higher levels of death anxiety. This line of reasoning suggested that the more highly one values oneself, the more disastrous the ultimate loss of one's self via death will be perceived. Quite to the contrary, the Davis et al. (1978) report and the present data indicate that those who do not value themselves highly are the ones who express the highest levels of death anxiety. As an alternate interpretation, we propose that those with low self-esteem simply have more fears or anxieties than do those with high self-esteem. The high, positive correlations between DAS scores and scores on the shortform TMAS reported by Tramill et al. (1982) support this contention.

Likewise, the Davis et al. (1978) data and the results of the present study indicate that in both instances, regardless of level of self-esteem, women had higher levels of death anxiety than did men. Since this same gender effect has been reported by several additional authors (e.g., Davis et al., 1983; Koob \& Davis, 1977; Sadowski et al., 1979; Templer et al., 1974; Tramill et al., 1982; Tramill et al., 1984) over a substantive period of time, it must be viewed as robust and durable. In view of the apparent strides made by women in many areas of society in recent years, the magnitude and durability of this effect might seem puzzling. However, it will be recalled that the DAS only measures the expressed fear of death. Possibly men are not as willing to overtly reveal such fears as women are. To do so would negate the "macho" image of men that permeates the media in such forms as Rambo and similar other movies. Clearly, additional research is needed for one to distinguish between the fear of death that one person is willing to share with another person as compared with the intensity of this fear that is known only to the individual. It appears reasonable to contend that there may be a substantial difference, especially for men.

\section{REFERENCES}

Davis, S. F., Bremer, S. A., Anderson, B. J., \& Tramill, J. L. (1983). The interrelationships of ego strength, self-esteem, death anxiety, and gender in undergraduate college students. Journal of General Psychology, 108, 55-59.

Davis, S. F., Martin, D. A., Wilee, C. T., \& Voorhees, J. W. (1978). Relationship of fear of death and level of self-esteem in college students. Psychological Reports, 42, 419-422.

DigGory, J. C., \& Rothman, D. Z. (1961). Values destroyed by death. Journal of Abnormal \& Social Psychology, 63, 205-210.

Ford, R. E., AleXander, M., \& Lester, D. (1971). Fear of death of those in a high stress occupation. Psychological Reports, 29, 502.

Helmreich, R., \& STAPP, J. (1974). Short forms of the Texas Social Behavior Inventory (TSBI), an objective measure of self-esteem. Bulletin of the Psychonomic Society, 4, 473-475.

Hicks, R. A., Ostle, J. R., \& Pellegrini, R. J. (1980). A unidimensional short form of the TMAS. Bulletin of the Psychonomic Society, 16, 447-448.

Howard, A., Pion, G. M., Gottfredson, G. D., Flattau, P. E., Oskamp, S., Pfafflin, S. M., Bray, D. W., \& Burstein, A. G (1986). The changing face of American psychology. American Psychologist, 41, 1311-1327.

Коов, P. B., \& DAvis, S. F. (1977). Fear of death in military officers and their wives. Psychological Reports, 40, 261-262.

MidDleton, W. C. (1936). Some reactions toward death among college students. Journal of Abnormal \& Social Psychology, 31, 165-173.

REID, D. W., \& WARE, E. E. (1973). Multidimensionality of internalexternal control: Implications for past and future research. Canadian Journal of Behavioural Sciences, 5, 264-271.

Sadowski, C. J., Davis, S. F., \& Loftus-Vergari, M. C. (1979). 
Locus of control and death anxiety: A reexamination. Omega, 10, 203-209.

SCHULz, R. (1978). The psychology of death, dying, and bereavement. Reading, MA: Addison-Wesley.

TEMPLER, D. I. (1970). The construction and validation of a death anxiety scale. Journal of General Psychology, 82, 165-177.

Templer, D. I., Lester, D., \& RufF, C. F. (1974). Fear of death and femininity. Psychological Reports, 35, 530.

Tramill, J. L., Davis, S. F., Bremer, S., Dudeck, M. M., \& ElsBURY, D. L. (1982). A proposed relationship between the unidimen- sional short form of the TMAS and the DAS: The effects of embedding vs. separate administration. Bulletin of the Psychonomic Society, 19, 209-211.

Tramill, J. L., Kleinhammer-Tramill, P. J., Davis, S. F., Parks, C. S., \& Alexander, D. (1984). The relationship between the Type A behavior pattern, fear of death, and manifest anxiety. Bulletin of the Psychonomic Society, 22, 42-44.

(Manuscript received April 24, 1989.) 